\title{
Interference of Notch 1 inhibits the proliferation and invasion of breast cancer cells: Involvement of the $\beta$-catenin signaling pathway
}

\author{
XI XI LAI ${ }^{1},{\text { GANG } \mathrm{LI}^{2}, \text { BAOCHAI LIN }}^{2}$ and HAN YANG ${ }^{2}$ \\ Departments of ${ }^{1}$ Respiratory Medicine and ${ }^{2}$ Radiation Oncology, The First Affiliated Hospital, \\ Wenzhou Medical University, Wenzhou, Zhejiang 325000, P.R. China
}

Received June 30, 2016; Accepted June 27, 2017

DOI: $10.3892 / \mathrm{mmr} .2017 .8161$

\begin{abstract}
Breast cancer is one of the most common types of carcinoma in humans. The aim of the present study was to identify the role of Notch 1 in the proliferation and invasion of human breast cancer cells. Firstly, the levels of Notch 1 were determined by western blot analysis in breast cancer cell lines, and the results revealed that the expression levels of Notch 1 were markedly higher in MDA-MB-231 and MCF-7 cells, and lower in MCF-10A cells, compared with human mammary epithelial cells. An MTT assay was used to determine the viability of breast cancer cells. The optical density (OD)490 values were significantly decreased in Notch 1 short hairpin (sh)RNA-transfected MCF-7 and MDA-MB-231 cells, compared with the OD490 values in the negative control shRNA-transfected cells. The MCF-7 cells and MDA-MB-231 cells were also treated with increasing concentrations of MRK003, a Notch 1 inhibitor, for 24, 48 and $72 \mathrm{~h}$, respectively. The inhibition rate was gradually increased in the MRK003-treated cells in a time- and dose-dependent manner. The invasive ability of the cells was determined using a Transwell migration assay. The migration ability was significantly decreased in the Notch 1-transfected MCF-7 cells and MDA-MB-231 cells. The molecular mechanism was examined, and the knockdown of Notch 1 significantly decreased the expression levels of $\beta$-catenin, matrix metalloproteinase (MMP)-2 and MMP-9, and was also correlated with the downregulation of $\beta$-catenin in the nucleus. In conclusion, Notch 1 was key in the progression of breast cancer, and knocking down the expression of Notch 1 significantly suppressed the proliferation and invasion of breast cancer cells. This provides novel clues for cancer therapy in human breast cancer.
\end{abstract}

Correspondence to: Mr. Han Yang, Department of Radiation Oncology, The First Affiliated Hospital, Wenzhou Medical University, 2 Fuxue Lane, Wenzhou, Zhejiang 325000, P.R. China E-mail: yanghanhope@163.com

Key words: Notch 1, $\beta$-catenin, breast cancer cells, matrix metalloproteinase-2

\section{Introduction}

Breast cancer is one of the most commonly diagnosed types of cancer in women worldwide, which usually develops from breast tissues, including the milk ducts or lobules (1). Breast cancer is the uncontrolled growth of malignant cells, and is associated with high incidence and high mortality rates. It is estimated that breast cancer comprises $11 \%$ of all types of cancer diagnosed worldwide on an annual basis (2). A combination treatment is used in the treatment of human breast cancer, including surgery, radiotherapy, chemotherapy, hormone therapy and biological therapy (3-5). Until now, surgery remains the most common treatment strategy for breast cancer. Traditional prognostic factors include age, menopausal status, status of axillary lymph nodes, tumor size, histological features, and estrogen and progesterone receptors (6), and the prognosis of breast cancer is closely associated with the invasion and metastasis early on. It is reported that peritoneal metastases $(7,8)$, lymph node metastasis $(9,10)$ and brain metastasis (11-13) in breast cancer are usually associated with a poor prognosis following standard treatments. The progression, invasion and metastasis of breast cancer involve multiple genetic mutations, leading to the activation of oncogenes and the inactivation of tumor suppressor genes $(14,15)$. Therefore, it is important to identify a novel and effective target in cancer-associated signaling pathways, which may assist in the treatment of breast cancer.

The Notch 1 signaling pathway is a highly conserved pathway in the majority of multicellular organisms $(16,17)$. It can maintain the character of adult stem cells by affecting the communication between adjacent cells. It is also involved in the tumorigenesis of various types of tumor by affecting differentiation, proliferation and apoptosis $(18,19)$. The activation of Notch has been reported to cause mammary carcinoma. $\mathrm{Xu}$ et al found that Notch receptors were of prognostic value in breast cancer, and that a high mRNA expression levels of Notch 1 were correlated with poor overall survival (OS) in patients with progesterone receptor-negative breast cancer (20). In addition, abnormal Notch 1 signaling was found to be important in patients with colorectal cancer (21). Pant et al reported on a first-in-human phase I study of the oral Notch inhibitor, LY900009, in patients with advanced cancer, and found that LY900009 inhibited plasma levels of amyloid- $\beta$ peptide in a 
dose-dependent manner with $80-90 \%$ inhibition observed in the 30-60-mg cohorts (22). Notch signaling has been reported as a novel therapeutic target to prevent the recurrence of breast cancer and regulate long non-coding (Lnc)RNAs at the downstream target of the Notch pathway. In breast cancer, it has been found that Notch 1 promotes cell proliferation by regulating the GAS5 LncRNA (19).

In the present study, the molecular mechanism underlying the effects of Notch 1 on the proliferation and invasion of human breast cancer cells was examined. In addition, the association between the Notch 1 signaling pathway and Wnt/ $\beta$-catenin signaling pathway, and the variation in $\beta$-catenin location were examined. The results may provide novel clues for determining whether Notch 1 may be used as a novel target in the treatment of breast cancer.

\section{Materials and methods}

Cell lines. The MDA-MB-231, MCF-7 and MCF-10A breast cancer cell lines were purchased from Shanghai Bioleaf Biotech Co., Ltd. (Shanghai, China). Human mammary epithelial cells (HMECs; cat no. A10565) isolated from adult female breast tissue were obtained from Thermo Fisher Scientific, Inc. (Waltham, MA, USA). The cells were cultured in Dulbecco's modified Eagle's medium (DMEM), which was purchased from GE Healthcare Life Sciences (Little Chalfont, UK) supplemented with $10 \%$ serum at $37^{\circ} \mathrm{C}$ in an atmosphere of $5 \% \mathrm{CO}_{2}$. Lentiviral particles of Notch 1 short hairpain (sh)RNA (cat no. sc-36095-V) and control (N.C.) shRNA lentiviral particles (cat no. sc-108080) were purchased from Santa Cruz Biotechnology, Inc. (Santa Cruz, CA, USA). MRK003 (cat no. 205885) was obtained from MedKoo Biosciences, Inc. (Chapel Hill, NC, USA). MTT reagent was obtained from Sigma-Aldrich; Merck KGaA (Darmstadt, Germany).

MTT assay. The breast cancer cells ( $3 \times 10^{5}$ cells/well) were plated into 48-well plates and transfected with Notch 1 shRNA or N.C. shRNA for 48, 72 and 96 h, respectively. The cell proliferation was then evaluated using an MTT assay. In a separate experiment, the breast cancer cells ( $3 \times 10^{5}$ cells/well) were treated with different concentrations of Notch 1 inhibitor, MRK003, for 24,48 and $72 \mathrm{~h}$, respectively at $37^{\circ} \mathrm{C}$. The concentrations of MRK003 were 0, 0.5, 1.0 and 5.0 $\mu \mathrm{M}$. MRR reagent (10 $\mu \mathrm{l}$ of $5 \mathrm{mg} / \mathrm{ml}$; Sigma-Aldrich; Merck KGaA) was added into the medium $4 \mathrm{~h}$ prior to assessment. Finally, $150 \mu \mathrm{l}$ of DMSO was added and the purple crystals were dissolved for $10 \mathrm{~min}$. The plates were read at a test wavelength of $490 \mathrm{~nm}$ and a reference wavelength of $570 \mathrm{~nm}$.

Western blot analysis. Breast cancer cell $\left(2 \times 10^{6}\right.$ cells/well $)$ lysates were prepared and $(15 \mu \mathrm{l})$ the proteins were separated by $10 \%$ SDS-PAGE. The polyvinylidene difluoride membrane was blocked with $5 \%$ bovine serum albumin and incubated with primary antibodies at $4{ }^{\circ} \mathrm{C}$ overnight and secondary antibodies for $1 \mathrm{~h}$ at room temperature, respectively. The antibodies used were as follows: Anti-Notch 1, anti-GSK-3 $\beta$, anti-MMP-2, anti-MMP-9, anti- $\beta$-catenin, anti- $\beta$-actin and horseradish peroxidase (HRP)-conjugated goat anti-mouse secondary antibody. The primary antibody against Notch 1 (mN1A; cat no. sc-32745; 1:1,000) was obtained from Santa
Cruz Biotechnology, Inc., which is a mouse monoclonal immunoglobulin (Ig)G1 provided at $200 \mu \mathrm{g} / \mathrm{ml}$. The GSK-3 $\beta$ antibody (H-76; cat no. sc-9166; 1:1,000) was obtained from Santa Cruz Biotechnology, Inc., and is a rabbit polyclonal IgG provided at $200 \mu \mathrm{g} / \mathrm{ml}$. The MMP2 antibody (cat no. 10373-2-AP; 1:1,000) and MMP-9 antibody (cat no. 10375-2-AP; 1:1,000) are rabbit polyclonal antibodies, and were obtained from Wuhan Sanying Biotechnology (Wuhan, China). The secondary goat anti-mouse IgG H\&L HRP-conjugated (cat no. ab6789; 1:5,000) and goat anti-rabbit IgG H\&L HRP-conjugated (cat no. ab6721; 1:5,000) were obtained from Abcam (Cambridge, UK). $\beta$-catenin antibody (cat no. ab16051; 1:1,000) was obtained from Abcam. $\beta$-actin antibody (cat no. HC201-01; 1:500) was purchased from TransGen Biotechnology (Beijing, China). The bands were visualized with an enhanced chemiluminescence detection system (GE Healthcare, Chicago, IL, USA) and protein levels were quantified using a gel imaging system Gel Doc ${ }^{\mathrm{TM}}$ XR system with Quantity One software (version 4.4) (both from Bio-Rad Laboratories, Inc., Hercules, CA, USA).

Transwell assay. The MCF-7 cells and MDA-MB-231 cells were cultured in DMEM medium supplemented with $10 \%$ fetal bovine serum (FBS). Transwell assays were performed using a 24-well format with $8-\mu \mathrm{m}$ pore size (cat no. ECM509; Chemicon International, Inc., Temecula, CA, USA). Briefly, the lower compartment was filled with $2 \mathrm{ml}$ of DMEM with $0.5 \%$ FBS containing $40 \mu \mathrm{g} / \mathrm{ml}$ collagen I, and the Transwell insert was placed into the medium in the lower compartment. Subsequently, 5x103 MCF-7 cells or MDA-MB-231 cells were plated in the upper compartment and incubated at $37^{\circ} \mathrm{C}$ and $5 \% \mathrm{CO}_{2}$ for $48 \mathrm{~h}$. The breast cancer cells on the lower side of the insert filter were then immediately fixed in 5\% glutaraldehyde for $10 \mathrm{~min}$, and stained with $1 \%$ crystal violet in $2 \%$ ethanol for $20 \mathrm{~min}$. The cells were washed with $\mathrm{ddH}_{2} \mathrm{O}$ and the numbers of cells on the lower side of the filter were counted under a light microscope.

Statistical analysis. The data were analyzed using the SPSS software version 19.0 (IBM Corp., Armonk, NY, USA). The expression levels of proteins, including Notch 1, and the migration rates of cells were analyzed with two sets of independent samples t-tests. The comparison of multiple groups was performed with multiple comparisons using a two-way analysis of variance and Dunnett's test. The experiment was repeated twice and there were three replicates for each well in the MTT assay. The data are presented as the mean \pm standard error of the mean.

\section{Results}

Expression levels of Notch 1 are higher in MDA-MB-231 and MCF-7 cells. In order to examine the role of Notch 1 in the progression of human breast cancer, three breast cancer cell lines were used as a cell model, including MDA-MB-231, MCF-10A and MCF-7 cells. MDA-MB-231 cells have a high invasive ability, whereas MCF10A cells are a non-invasive cell line. Usually, MCF-7 breast cancer cells have a poor invasive phenotype. Normal HMECs were used as negative controls. The expression levels of Notch 1 were detected using western blot analysis. As shown in Fig. 1, the results demonstrated 
that the levels of Notch 1 were significantly increased in the MDA-MB-231 and MCF-7 cells $(\mathrm{P}<0.01)$, compared with levels in the HMECs. However, the level of Notch 1 was lower in the MCF-10A cells, compared with the HMECs $(\mathrm{P}<0.05)$.

Knock down of the expression of Notch 1 significantly inhibits the proliferation of breast cancer cells. In order to determine the role of Notch 1 in the proliferation of breast cancer cells, MCF-7 cells were transfected with Notch 1 shRNA and N.C. shRNA for 48,72 and $96 \mathrm{~h}$, respectively. The cell viability (OD 490 value) was significantly lower in the Notch 1 -transfected MCF-7 cells, compared with that in the N.C. shRNA-transfected MCF-7 cells ( $\mathrm{P}<0.01$; Fig. 2A). This was consistent with the results in MDA-MB-231 cells (Fig. 2B). Taken together, these results demonstrated that Notch 1 was an important in promoting the proliferation of breast cancer cells.

MRKO03 inhibits the proliferation of MCF-7 and MDA-MB-231 cells in a time- and dose-dependent manner. MRK003 is a potent and selective $\gamma$-secretase inhibitor, which can lead to the downregulation of the nuclear Notch 1 intracellular domain and inhibits the role of Notch 1 (23). In order to further confirm the role of Notch 1 in breast cancer cells, the present study used different concentrations of MRK003 $(0.0,0.5,1.0$ and $5.0 \mu \mathrm{M})$ for 24,48 and $72 \mathrm{~h}$, respectively. As shown in Fig. 3A, MRK003 effectively inhibited the proliferation of MCF-7 cells as the concentration of the Notch 1 inhibitor increased. In addition, the inhibition rate was significantly increased in a time-dependent manner $(\mathrm{P}<0.01)$. This was consistent with the results in the invasive MDA-MB-231 cell line (Fig. 3B). These results demonstrated that inhibiting Notch 1 by MRK003, the Notch 1 inhibitor, significantly suppressed the proliferation of breast cancer cells in a doseand time-dependent manner.

Notch 1 knockdown inhibits the invasive ability of MCF-7 and MDA-MB-231 cells. To further examine the effects of Notch 1 on the invasive ability of the MCF-7 and MDA-MB-231 breast cancer cells, a Transwell assay was performed to detect the effects of Notch 1 on cell invasion. The MCF-7 cells or MDA-MB-231 cells were transfected with Notch 1 shRNA or N.C. shRNA and cultured for $48 \mathrm{~h}$, and the invasive cells were observed, as shown in Fig. 4A. The results demonstrated

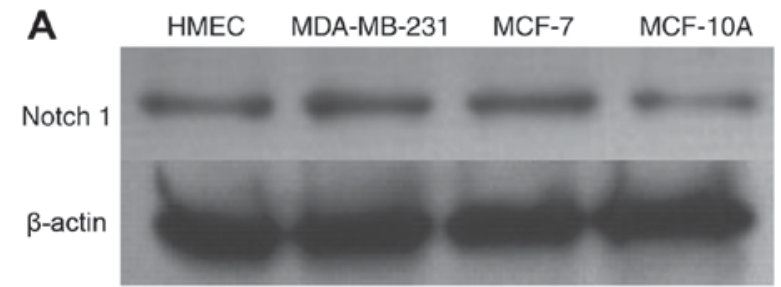

B

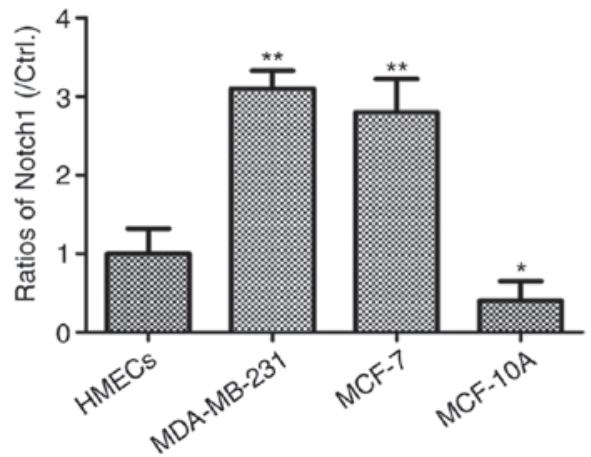

Figure 1. Expression levels of Notch 1 are higher in MDA-MB-231 and MCF-7 cells. (A) Breast cancer cell lines (MDA-MB-231, MCF-7 and MCF-10A) were plated on a 48-well plate. The cells were cultured for $24 \mathrm{~h}$ and cell lysates were prepared to detect endogenous Notch 1 using western blot analysis. B-actin was used as the internal reference gene. (B) Gray values of Notch 1 in MDA-MB-231, MCF-7, MCF-10A and HMECs cells are shown. ${ }^{*} \mathrm{P}<0.05$ and ${ }^{* *} \mathrm{P}<0.01$, compared with the HMECs. Ctrl, control.

that the migration rate of the Notch 1 shRNA-transfected cells was significantly decreased, compared with that of the N.C. shRNA-transfected cells (Fig. 4B), suggesting that the Notch 1 signaling pathway may contribute to the invasion and migration of breast cancer cells.

Interference with Notch 1 reduces the expression of $\beta$-catenin, $M M P-2$ and MMP-9. The present study also investigated whether knockdown of the expression of Notch 1 affected the $\beta$-catenin signaling pathway. The MDA-MB-231 cells were transfected with Notch 1 shRNA and N.C. shRNA for $48 \mathrm{~h}$, and the levels of GSK- $3 \beta$ and $\beta$-catenin were determined using western blot analysis. As exhibited in Fig. 5, the expression levels of $\beta$-catenin, MMP-2 and MMP-9 were significantly decreased in the Notch 1 shRNA-transfected MDA-MB-231
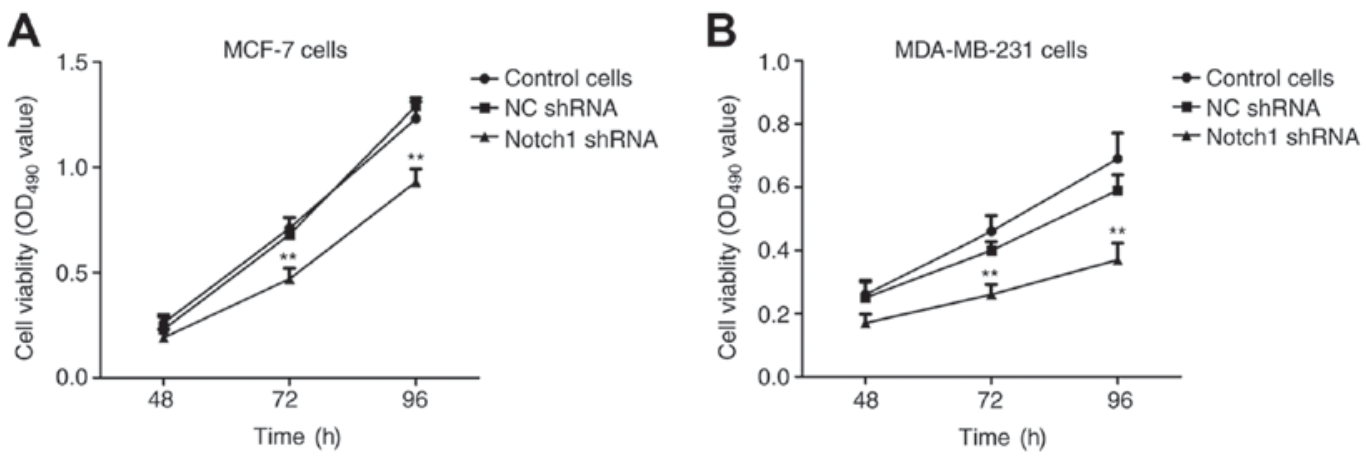

Figure 2. Knockdown of the expression of Notch 1 significantly inhibits the proliferation of breast cancer cells. The (A) MCF-7 and (B) MDA-MB-231 human breast cancer cells were plated into a 48 -well plate and transfected with Notch 1 shRNA or NC shRNA for 48,72 and 96 h, respectively. The cell viability was determined using an MTT assay. Untreated cells were included as a negative control. ${ }^{* *} \mathrm{P}<0.01$, compared with NC. shRNA-transfected cells. shRNA, short hairpin RNA; NC, negative control; OD, optical density. 
A

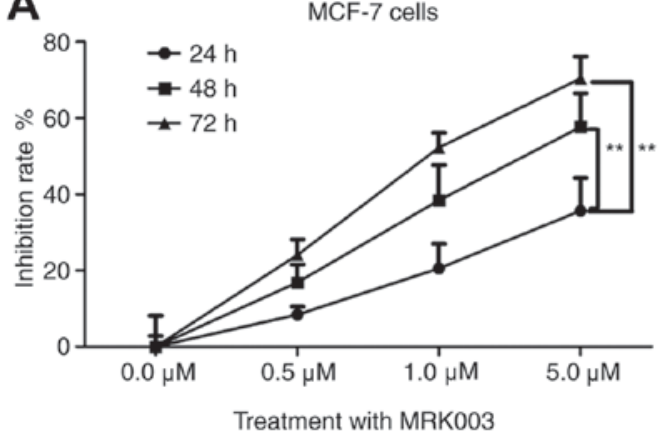

B

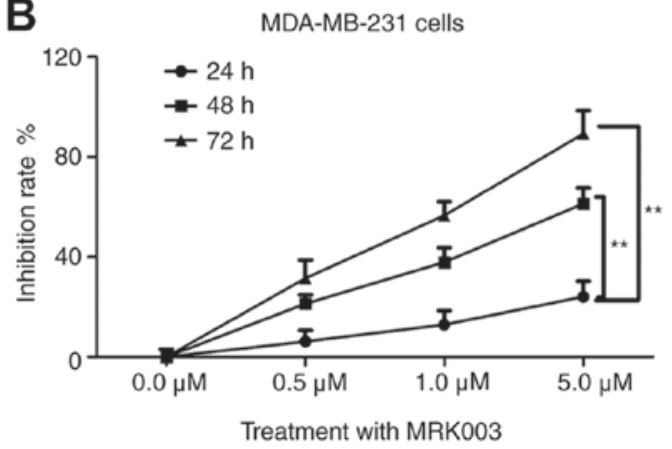

Figure 3. MRK003 inhibits the proliferation of MCF-7 and MDA-MB-231 cells in a time- and dose-dependent manner. (A) MCF-7 and (B) MDA-MB-231 breast cancer cells were treated with increasing concentrations of Notch 1 inhibitor, MRK003, for 24, 48 and $72 \mathrm{~h}$, respectively. The MRK003 concentrations were $0.5,1.0$ and $5.0 \mu \mathrm{M}$. Untreated breast cancer cells were included as a negative control. ${ }^{* *} \mathrm{P}<0.01$ between the groups.

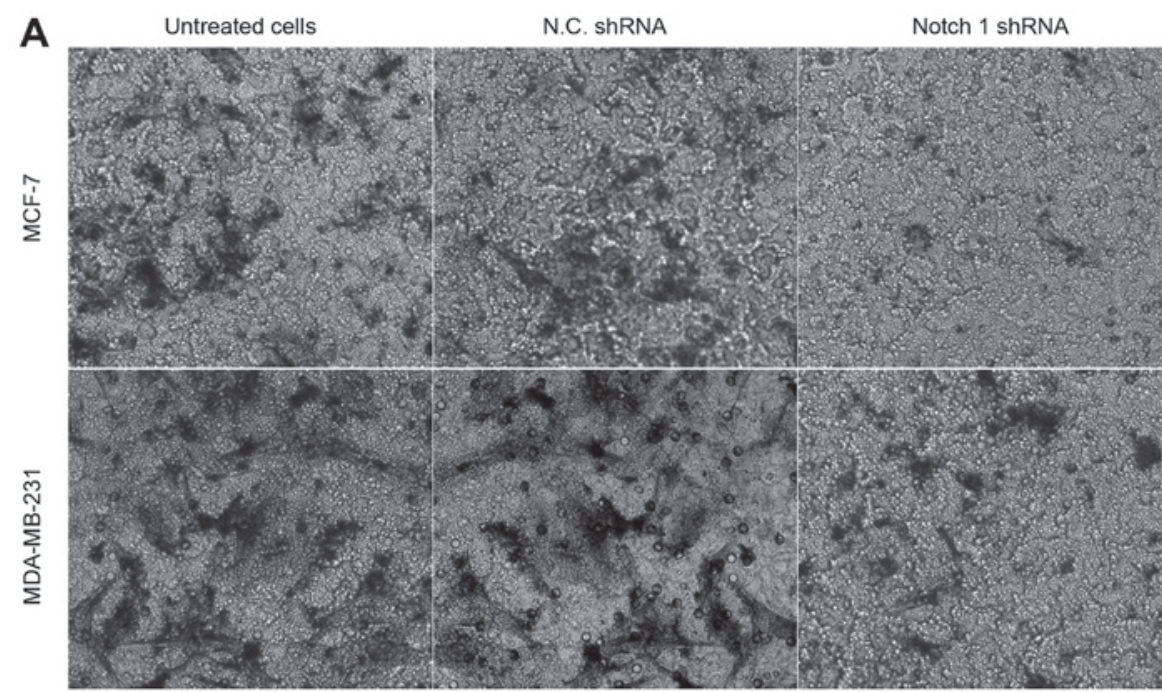

B

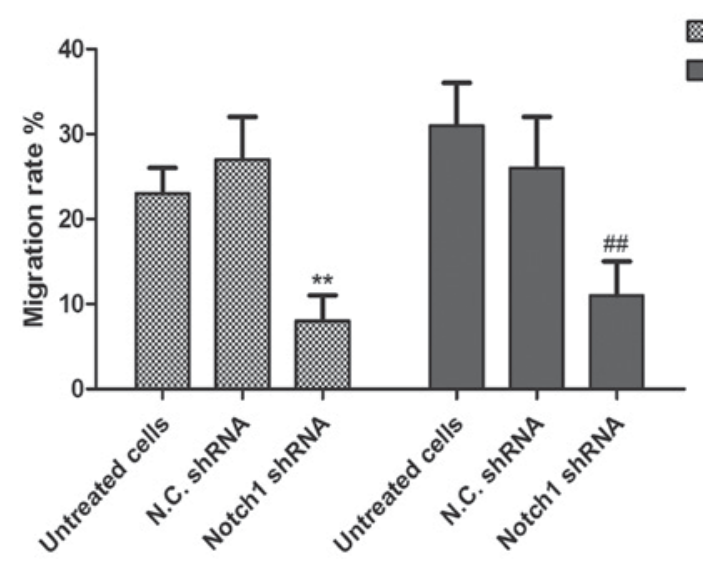

Figure 4. Knockdown of Notch 1 inhibits the invasive ability of MCF-7 and MDA-MB-231. (A) MCF-7 and MDA-MB-231 human breast cancer cells were transfected with Notch 1 shRNA or N.C. shRNA and cultured for $48 \mathrm{~h}$. Untreated cells and N.C. shRNA-transfected breast cancer cells were used as negative controls. Magnification, $\mathrm{x} 200$ ). (B) Migration rates in the different groups are shown. ${ }^{* *} \mathrm{P}<0.01$, compared with N.C. shRNA-transfected MCF-7 cells. ${ }^{\# \#} \mathrm{P}<0.01$, compared with N.C. shRNA-transfected MDA-MB-231 cells. shRNA, short hairpin RNA; N.C., negative control.

cells, compared with levels in the N.C. shRNA-transfected cells. However, no significant change in the expression level of GSK-3 $\beta$ was observed, compared with the N.C. shRNA-transfected cells $(\mathrm{P}>0.05)$. These results demonstrated that Notch 1 , as an oncogene in breast cancer cells, promoted the proliferation and invasion of breast cancer cells partly by regulating
MMP-2 and MMP-9 involving the $\beta$-catenin-related signaling pathway.

Interference with Notch 1 decreases the levels of nuclear $\beta$-catenin in MDA-MB-231 cells. To examine whether the knockdown of Notch 1 affected the translocation of $\beta$-catenin 
A

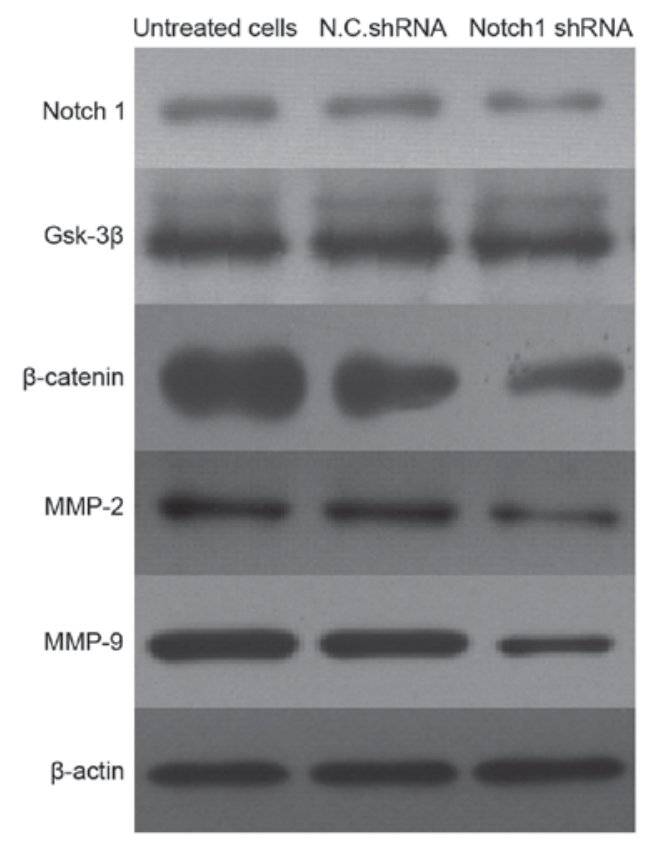

B
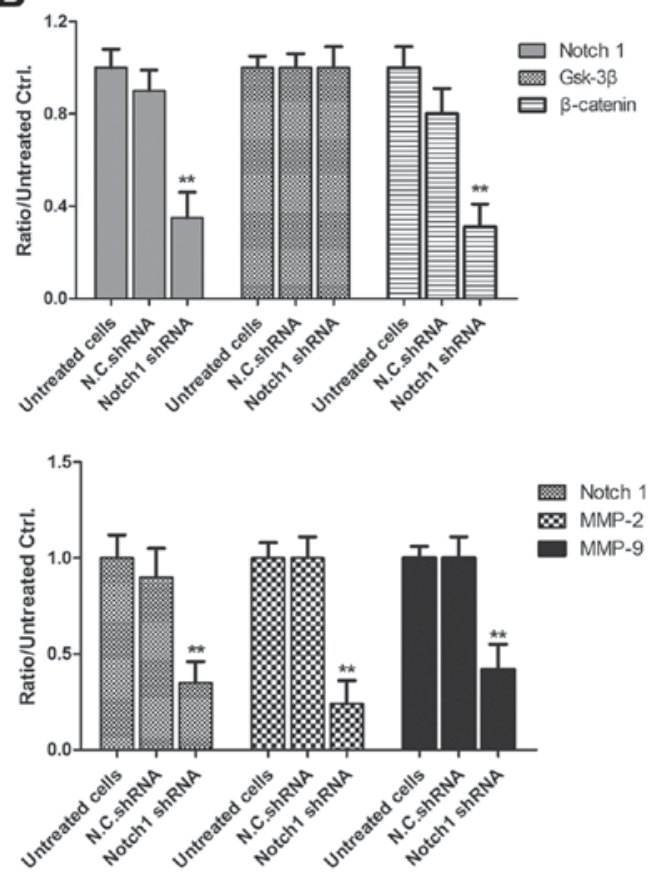

Figure 5. Interference with Notch 1 reduces the expression of $\beta$-catenin, MMP-2 and MMP-9. (A) MDA-MB-231 cells were transfected with Notch 1 shRNA or N.C. shRNA for $48 \mathrm{~h}$, and the levels of Notch 1, GSK-3 $\beta$, $\beta$-catenin, MMP-2 and MMP-9 were determined using western blot analysis. (B) Gray values of Notch 1, GSK-3 $\beta$, $\beta$-catenin, MMP-2 and MMP-9 are shown. ${ }^{* *} \mathrm{P}<0.01$, compared with N.C. shRNA-transfected cells. MMP, matrix metalloproteinase; GSK-3 $\beta$, glycogen synthase kinase $3 \beta$; shRNA, short hairpin RNA; N.C., negative control.

A

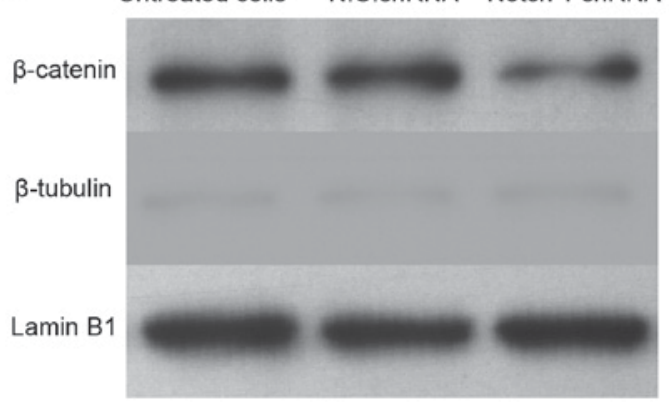

B

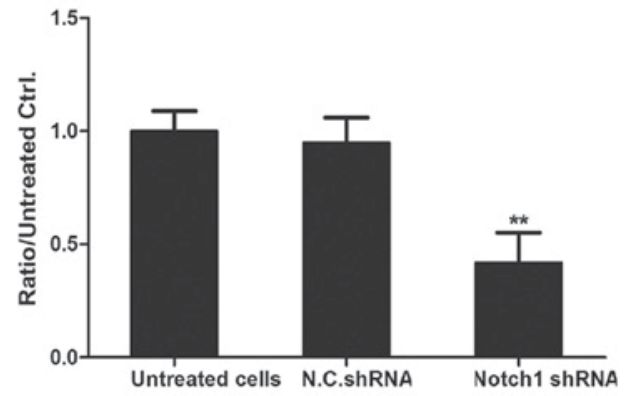

Figure 6. Interference with Notch 1 decreases the levels of nuclear $\beta$-catenin in MDA-MB-231 cells. The MDA-MB-231 cells were transfected with Notch 1 shRNA or N.C. shRNA for $48 \mathrm{~h}$. The levels of nuclear $\beta$-catenin were determined using western blot analysis. N.C. shRNA-transfected cells were used as negative controls. Lamin B1 was used as the nuclear reference gene and $\beta$-tubulin was used as the cytoplasmic reference gene. (B) Gray values of $\beta$-catenin are shown. ${ }^{* *} \mathrm{P}<0.01$, compared with N.C. shRNA-transfected cells. shRNA, short hairpin RNA; N.C., negative control.

in MDA-MB-231 cells, the levels of nuclear Notch 1 were determined using western blot analysis. As exhibited in Fig. 6, the expression of Notch 1 in the nucleus was significantly decreased in the Notch 1 shRNA-transfected MDA-MB-231 cells, compared with expression in the N.C. shRNA-transfected cells. Therefore, it was hypothesized that downstream target genes, including cyclin D1, c-Myc and other associated genes, may be downregulated in Notch 1 shRNA-interference of MDA-MB-231 cells.

\section{Discussion}

Breast cancer is the second most frequently diagnosed cancer in women and is life threatening. The mechanism underlying the tumorigenesis of breast cancer has been investigated previously, involving the regulation of the $\mathrm{p} 38 /$ mitogen-activated protein kinase (MAPK) signal transduction pathway (24), the c-Jun $\mathrm{N}$-terminal kinase/stress-activated protein kinase signaling pathway (25), MAPK/extracellular signal-regulated signaling pathway (26) and human epidermal growth factor receptor 2 signaling pathway (27). The Notch 1 signaling pathway is also reported to be a highly conserved signaling pathway, which is found to regulate the development and progression of cancer $(18,28)$. In the present study, it was found that the Notch 1 signaling pathway was important in the proliferation and invasion of breast cancer cells.

In the present study, three breast cancer cell lines were cultured and the levels of Notch 1 were detected using western blot analysis. The results showed that the levels of Notch1 were higher in the invasive cell lines (MDA-MB-231 and 
MCF-7 cells), compared with that in the non-invasive cell line (MCF10A). The results also showed that Notch 1 was abnormally expressed in human breast cancer cell lines, suggesting Notch 1 may be involved in the proliferation and invasion of breast cancer cells. This was confirmed by the results of a Transwell assay, suggesting that Notch 1 had a higher potential to promote the invasion and migration of breast cancer cells.

The molecular mechanisms and the role of Notch 1 in breast cancer were also investigated. A number of studies have demonstrated that the dysregulation and abnormality of conserved Wnt $/ \beta$-catenin signaling occurs in human breast cancer $(29,30)$. The present study further examined the interplay between the Notch 1 and Wnt/ $\beta$-catenin signaling pathway. The results of the western blot analysis revealed that the knockdown of endogenous Notch 1 significantly decreased the expression of $\beta$-catenin and downregulated the levels of nuclear $\beta$-catenin. The expression levels of MMP-2 and MMP-9 were also detected using western blot analysis, and the results demonstrated that knockdown of the expression of Notch 1 significantly decreased the expression of MMP-2 and MMP-9, suggesting that the invasive ability was suppressed in the Notch 1 shRNA-transfected cells. Consistent with this, cell viability was significantly decreased in the Notch 1 shRNA-transfected MCF-7 and MDA-MB-231 cells, compared with that in the N.C. shRNA-transfected cells.

Taken together, the present study found that the knockdown of Notch 1 decreased the levels of MMP-2 and MMP-9 in human breast cancer cells, which was consistent with previous evidence that MMP-2 and MMP-9 correlate significantly with tumor size (28), invasion and metastasis in breast cancer (31). In terms of the underlying molecular mechanism, it may be that the inhibition of Notch 1 significantly suppressed the proliferation and invasion of breast cancer cells by decreasing the $\beta$-catenin signaling pathway. Therefore, it was concluded that Notch 1 is important in the progression and invasion of breast cancer, and may be used as a target in therapy for patients with breast cancer.

\section{References}

1. Wang Y, Yu J, Cui R, Lin J and Ding X: Curcumin in treating breast cancer: A review. J Lab Autom 21: 723-731, 2016.

2. Asif HM, Sultana S, Ahmed S, Akhtar N and Tariq M: HER-2 positive breast cancer - a mini-review. Asian Pac J Cancer Prev 17: 1609-1615, 2016.

3. Zhu L, Li L, Li Y, Wang J and Wang Q: Chinese herbal medicine as an adjunctive therapy for breast cancer: A systematic review and meta-analysis. Evid Based Complement Alternat Med 2016 9469276, 2016

4. George BP and Abrahamse H: A review on novel breast cancer therapies: Photodynamic therapy and plant derived agent induced cell death mechanisms. Anticancer Agents Med Chem 16: 793-801, 2016.

5. Nicolini A, Carpi A, Ferrari P, Biava PM and Rossi G: Immunotherapy and hormone-therapy in metastatic breast cancer: A review and an update. Curr Drug Targets 17: 1127-1139, 2016.

6. van Nijnatten TJ, Schipper RJ, Lobbes MB, Nelemans PJ, Beets-Tan RG and Smidt ML: The diagnostic performance of sentinel lymph node biopsy in pathologically confirmed node positive breast cancer patients after neoadjuvant systemic therapy: A systematic review and meta-analysis. Eur J Surg Oncol 41: 1278-1287, 2015

7. Bertozzi S, Londero AP, Cedolini C, Uzzau A, Seriau L, Bernardi S, Bacchetti S, Pasqual EM and Risaliti A: Prevalence, risk factors, and prognosis of peritoneal metastasis from breast cancer. Springerplus 4: 688, 2015.
8. Petekkaya I, Ayyildiz V, Kizilarslanoglu MC, Sahin U, Gezgen G, Roach EC, Karcaaltincaba M and Altundag K: Prognosis of breast cancer in patients with peritoneal metastasis. Breast 21: 420-421, 2012.

9. Yasuoka H, Tsujimoto M, Yoshidome K, Nakahara M, Kodama R, Sanke T and Nakamura Y: Cytoplasmic CXCR4 expression in breast cancer: Induction by nitric oxide and correlation with lymph node metastasis and poor prognosis. BMC Cancer 8: 340 , 2008.

10. Wu MQ, Hu P, Gao J, Wei WD, Xiao XS, Tang HL, Li X, Ge QD, Jia WH, Liu RB and Xie XM: Low expression of tyrosine-protein phosphatase nonreceptor type 12 is associated with lymph node metastasis and poor prognosis in operable triple-negative breast cancer. Asian Pac J Cancer Prev 14: 287-292, 2013.

11. Venkitaraman R, Joseph T, Dhadda A, Chaturvedi A and Upadhyay S: Prognosis of patients with triple-negative breast cancer and brain metastasis. Clin Oncol (R Coll Radiol) 21: 729-730, 2009.

12. Wikman H, Westphal L, Schmid F, Pollari S, Kropidlowski J, Sielaff-Frimpong B, Glatzel M, Matschke J, Westphal M, Iljin K, et al: Loss of CADM1 expression is associated with poor prognosis and brain metastasis in breast cancer patients. Oncotarget 5: 3076-3087, 2014.

13. Yamamura J, Masuda N, Yasojima H, Mizutani M, Kuriyama K, Nakamori S, Sekimoto M, Mano M, Tanaka E and Nonaka M: Clinicopathological factors related to the prognosis of metastatic breast cancer patients after development of brain metastasis. Breast Care (Basel) 10: 387-392, 2015.

14. Li Y, Jin K, van Pelt GW, van Dam H, Yu X, Mesker WE, Ten Dijke P, Zhou F and Zhang L: c-Myb enhances breast cancer invasion and metastasis through the Wnt/ $\beta$-Catenin/Axin2 pathway. Cancer Res 76: 3364-3375, 2016.

15. Shi M, Cao M, Song J, Liu Q, Li H, Meng F, Pan Z, Bai J and Zheng J: PinX1 inhibits the invasion and metastasis of human breast cancer via suppressing NF- $\mathrm{B}$ /MMP-9 signaling pathway. Mol Cancer 14: 66, 2015.

16. D'Angelo RC, Ouzounova M, Davis A, Choi D, Tchuenkam SM, Kim G, Luther T, Quraishi AA, Senbabaoglu Y, Conley SJ, et al: Notch reporter activity in breast cancer cell lines identifies a subset of cells with stem cell activity. Mol Cancer Ther 14: 779-787, 2015.

17. Zhang W and Grivennikov SI: Top Notch cancer stem cells by paracrine NF- $\kappa \mathrm{B}$ signaling in breast cancer. Breast Cancer Res 15: 316, 2013.

18. Zhang Q, Yuan Y, Cui J, Xiao T and Jiang D: Paeoniflorin inhibits proliferation and invasion of breast cancer cells through suppressing Notch-1 signaling pathway. Biomed Pharmacother 78: 197-203, 2016.

19. Pei J and Wang B: Notch-1 promotes breast cancer cells proliferation by regulating LncRNA GAS5. Int J Clin Exp Med 8: 14464-14471, 2015.

20. Xu J, Song F, Jin T, Qin J, Wu J, Wang M, Wang Y and Liu J: Prognostic values of Notch receptors in breast cancer. Tumour Biol 37: 1871-1877, 2016.

21. Vinson KE, George DC, Fender AW, Bertrand FE and Sigounas G: The Notch pathway in colorectal cancer. Int J Cancer 138: 1835-1842, 2016.

22. Pant S, Jones SF, Kurkjian CD, Infante JR, Moore KN, Burris HA, McMeekin DS, Benhadji KA, Patel BK, Frenzel MJ, et al: A first-in-human phase I study of the oral Notch inhibitor, LY900009, in patients with advanced cancer. Eur J Cancer 56: $1-9,2016$.

23. Mizuma M, Rasheed ZA, Yabuuchi S, Omura N, Campbell NR, de Wilde RF, De Oliveira E, Zhang Q, Puig O, Matsui W, et al: The gamma secretase inhibitor MRK-003 attenuates pancreatic cancer growth in preclinical models. Mol Cancer Ther 11: 1999-2009, 2012

24. Jiang X, Li T and Liu RH: $2 \alpha$-Hydroxyursolic acid inhibited cell proliferation and induced apoptosis in MDA-MB-231 human breast cancer cells through the p38/MAPK signal transduction pathway. J Agric Food Chem 64: 1806-1816, 2016.

25. Wang HT and Wang CQ: 27-O-(E)-p-coumaric acyl ursolic acid via JNK/SAPK signal pathway regulates apoptosis of human breast cancer MDA-MB-231 cell line. Zhongguo Zhong Yao Za Zhi 40: 722-726, 2015 (In Chinese).

26. Zhang Y, Song M, Cui ZS, Li CY, Xue XX, Yu M, Lu Y, Zhang SY, Wang EH and Wen YY: Down-regulation of TSG101 by small interfering RNA inhibits the proliferation of breast cancer cells through the MAPK/ERK signal pathway. Histol Histopathol 26: 87-94, 2011. 
27. Lin YJ,Huang YH,Zhen YZ, Liu XJ and Zhen YS: Rhein lysinate induces apoptosis in breast cancer SK-Br-3 cells by inhibiting HER-2 signal pathway. Yao Xue Xue Bao 43: 1099-1105, 2008 (In Chinese)

28. Zhou X, Teng L and Wang M: Distinct prognostic values of four-Notch-receptor mRNA expression in ovarian cancer. Tumour Biol 37: 6979-6985, 2016.

29. Ranogajec I, Jakić-Razumović J, Puzović V and Gabrilovac J: Prognostic value of matrix metalloproteinase-2 (MMP-2), matrix metalloproteinase-9 (MMP-9) and aminopeptidase N/CD13 in breast cancer patients. Med Oncol 29: 561-569, 2012.
30. Yi SJ, Li LL and Tu WB: MiR-214 negatively regulates proliferation and WNT/ $\beta$-catenin signaling in breast cancer. Eur Rev Med Pharmacol Sci 20: 5148-5154, 2016.

31. Huang Y, Zhao K, Hu Y, Zhou Y, Luo X, Li X, Wei L, Li Z, You Q, Guo Q and Lu N: Wogonoside inhibits angiogenesis in breast cancer via suppressing Wnt/ $\beta$-catenin pathway. Mol Carcinog 55: 1598-1612, 2016. 